\title{
REGIONAL AGRICULTURAL WATER FOOTPRINT AND CROP WATER CONSUMPTION STUDY IN YELLOW RIVER BASIN, CHINA
}

\author{
YIN, J. ${ }^{1,2^{*}}-\mathrm{LU}, \mathrm{Y}^{3}-\mathrm{OU}, \mathrm{Z}^{2}$ \\ ${ }^{1}$ Research Center for China Western Modernization, Guizhou University of Finance and \\ Economics, University City, Huaxi District, Guiyang 550025, China \\ ${ }^{2}$ School of Water Conservancy and Civil Engineering, Northeast Agricultural University, \\ No. 59, MuCai Rd., Xiangfang Dist., Harbin 150030, China \\ ${ }^{3}$ GuoYuan Securities Co., Ltd, 18 Meishan Road, Shushan District, Hefei 230031, China \\ *Corresponding author \\ e-mail: yinjianbnu@163.com
}

(Received 16 ${ }^{\text {th }}$ Dec 2018; accepted $21^{\text {st }}$ Mar 2019)

\begin{abstract}
The 12 main crops in the Yellow River Basin were selected as the research objects. Based on crop water consumption and effective precipitation, the regional crop water consumption and agricultural water footprint of the Yellow River Basin are studied. The results showed that the distribution of crop water consumption in the Yellow River Basin was similar to that of the annual average precipitation. Irrigation affected the data distribution in some areas. The areas with high crop water consumption value were mainly concentrated in the irrigation areas along the Yellow River. Rain-fed agriculture was dominant in other areas, and crop water consumption was relatively small. The total crop water consumption in the Yellow River Basin was 84.25 billion $\mathrm{m}^{3}$ in 2017, 66\% of which is in Henan and Shandong provinces and $60 \%$ is for wheat and maize. The proportion of green water to crop water consumption in the Yellow River Basin was 78.7\%. The spatial distribution of green water consumption in crops was basically the same as that of crop water consumption. The agricultural water footprint of the Yellow River Basin is 49.45 billion $\mathrm{m}^{3}$, accounting for $58.7 \%$ of the crop water consumption. The proportion of green water consumption to total water consumption of most crops is more than $80 \%$, and the lowest is $58 \%$ for wheat. $56 \%$ of blue water in the river basin is used for wheat. Crop water consumption coefficient reflects the level of water use in production. The average crop water consumption coefficient in the Yellow River Basin is about $0.622 \mathrm{~m}^{3} / \mathrm{kg}$.
\end{abstract}

Keywords: water consumption coefficient distribution, annual average precipitation, reference evapotranspiration, green water, blue water

\section{Introduction}

Humanity's direct need of fresh water is mainly due to food production, among which green water has a function that cannot be ignored on food production (Veettil and Mishra, 2016). The green water is a water resource that comes from precipitation, is stored in soil and consumed by evaporation of vegetation (Zuo et al., 2015). Green water has made outstanding contributions to crop production (Hoff et al., 2010). Thus the need to consider this resource in water availability and water scarcity studies (Fader et al., 2011). Water for agricultural irrigation in the Yellow River Basin, China is mainly originated from precipitation, and the role of green water is more prominent (Zhang et al., 2014). Defining the characteristics of human need for agricultural water helps to find a way of increasing agricultural production and reducing agricultural water consumption (Feng et al., 2012). In the Yellow River Basin, water is less efficiently consumed for agricultural irrigation. Less than half of irrigation water resource 
consumed by agriculture is consumed by humans. In the Yellow River Basin in which the situation of agricultural water is grim, water is wasted in large quantities (Xiang et al., 2017). Coupled with imperfect water conservancy facilities, unreasonable watersaving irrigation system and unreasonable planting structure, the water consumption efficiency is very low in the basin (Gonçalves et al., 2007; Bai et al., 2017). Therefore, improving efficiency of irrigating water and giving full play to green water in the Yellow River Basin is an important way to improve efficiency of agricultural water, develop water-saving high-efficiency agriculture and alleviate the lack of water resource in the basin (Zhuo et al., 2014). A systematic analysis of the agricultural water footprint and crop water consumption in the basin provides the necessary scientific support for regional water resources safety and eco-economic system.

Crop water consumption, as a key indicator of analyzing the agricultural water footprint, is generally represented by the (evapotranspiration, ET) and subject to the calculation method of ET at the regional scale (González-Dugo et al., 2013; Yin et al., 2017; Wang et al., 2018). The difference is that when the ET at the regional scale is estimated, ET values of only a plant are selected at several moments (Serrano-Coronel et al., 2018). However, as there are multiple agricultural crops planted, calculation of agricultural water consumption should be subject to the amount of water consumed by all crops in their growth duration (Zhang et al., 2010). In addition, when the spatial distribution of water consumption of crops in growth duration is calculated, the existing research generally measures the amount of water that the crop takes up from the soil according to the water balance of the crops in the grid at the beginning and end of the growth duration to reduce the computational work. However, there are many factors affecting soil water content during the growth duration, beside crop water consumption (Mo et al., 2009; Li et al., 2016). Thus, subdividing the growth duration can approximate to the real facts. In order to improve the computational accuracy, inclusion of major crops in the study area, subdivision of the growth duration and use of high spatial resolution data is also a development direction (Barbagallo et al., 2004; Wei et al., 2016). In addition, advancement of remote sensing technique also provides the necessary conditions for monitoring crop water consumption in a real-time manner (Calera et al., 2017).

The 12 major crops in eight provinces of the Yellow River Basin are selected to analyze the spatial distribution of agricultural water consumption and green water consumption. Additionally, water consumption and primary industry water footprint are used as a basis to further study the agricultural water footprint. In order to provide support for formulating appropriate agricultural water-saving measures and ensuring the efficient and rational utilization of regional agricultural water resources.

\section{Materials}

\section{The study area}

The Yellow River originates from the Qinghai-Tibet Plateau and flows into the Bohai Sea. It flows through nine provinces (regions) including Qinghai, Sichuan, Gansu, Ningxia, Inner Mongolia, Shanxi, Shaanxi, Henan and Shandong, with $795,000 \mathrm{~km}^{2}$ drainage area and $5464 \mathrm{~km}$ total length of the main river channel (Fig. 1). Of the Yellow River Basin, the terrain is rugged violently, descending in three steps from west to east. During 1956 to 2017 , the average temperature of the basin is $8.6{ }^{\circ} \mathrm{C}$; the average annual precipitation is $466 \mathrm{~mm}$, decreasing from the southeast to the 
northwest (Fig. 2); the annual sunshine hours fall between 1400 and $3300 \mathrm{~h}$. The climate difference is distinct. The west is arid and the east is humid; The basin is divided by water condition into semi-humid region, semi-arid region and arid region from west to east, and by temperature condition into warm temperate zone, the middle temperate zone and the plateau climate zone.

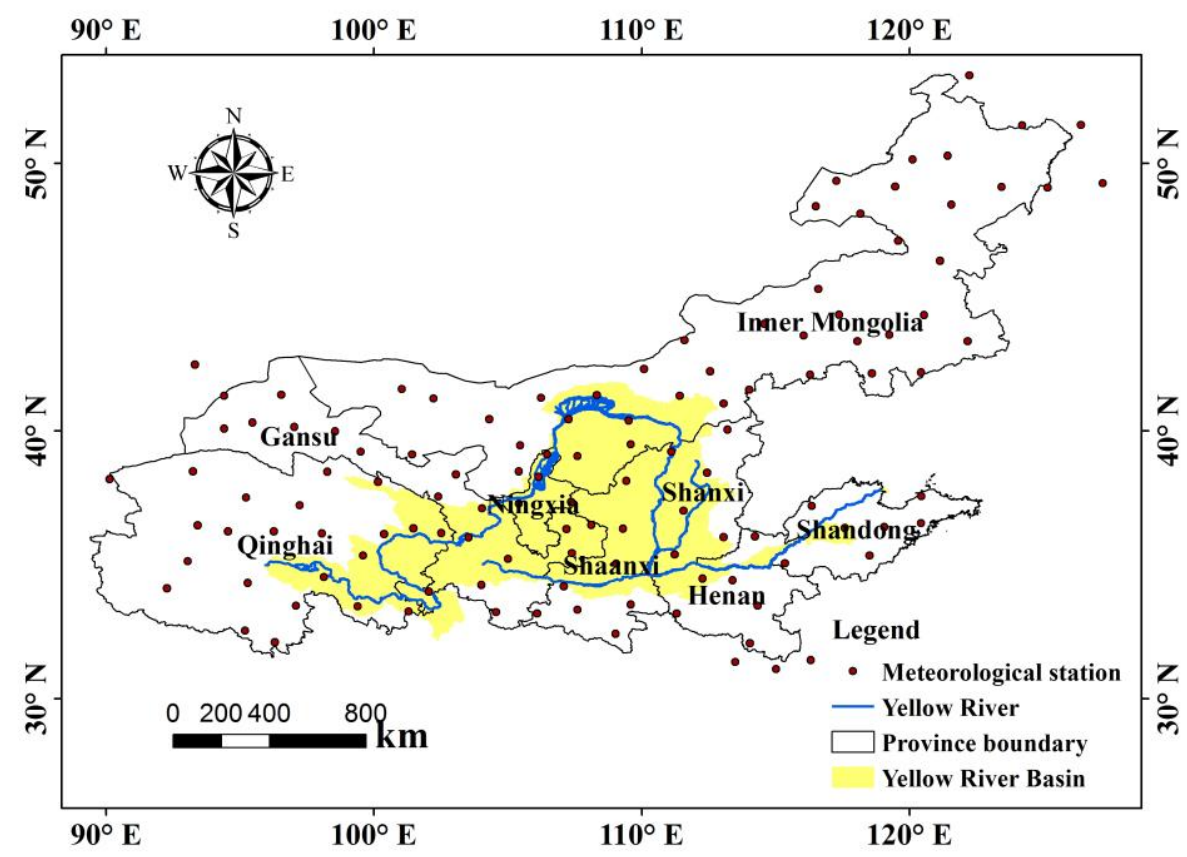

Figure 1. The map of the Yellow River Basin and the related nine provinces

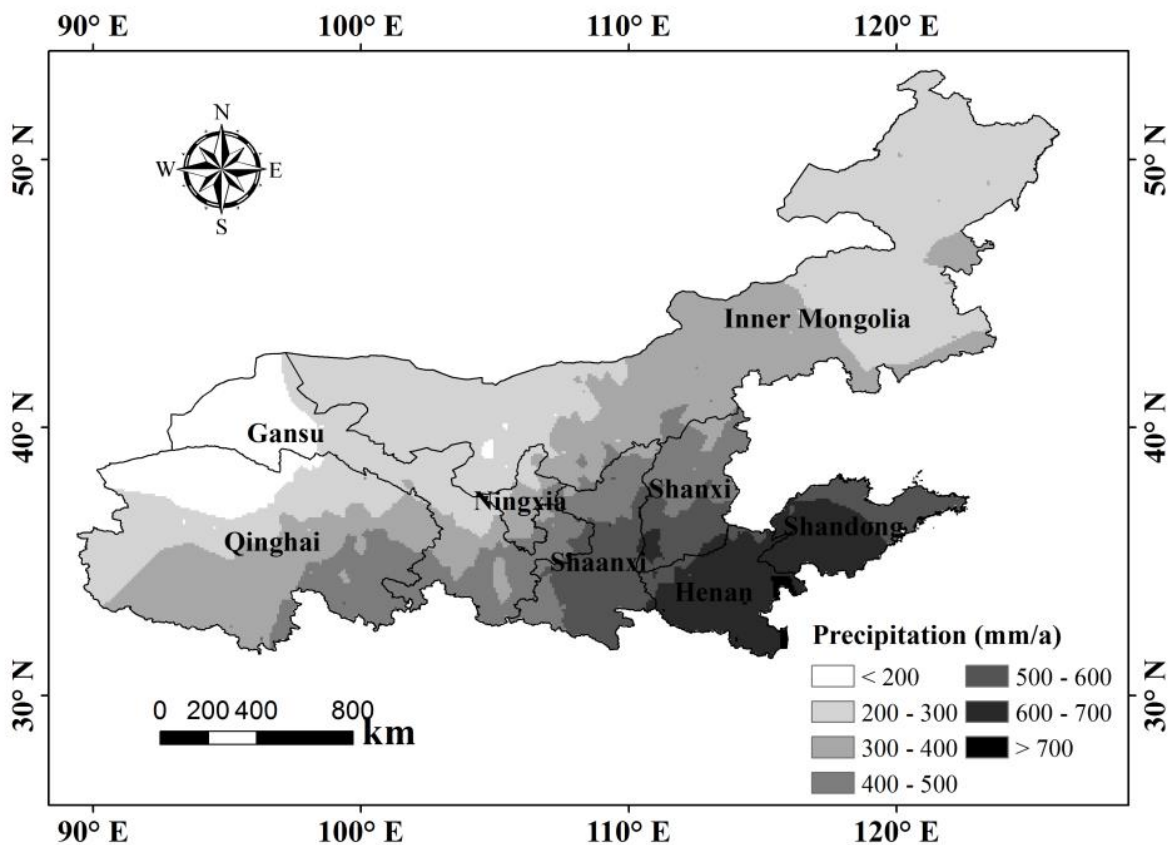

Figure 2. Spatial distribution of annual average precipitation in the Yellow River Basin (19562017) 


\section{Data}

The planting area and yield data of the crop are obtained from the global major crop distribution map and yield distribution map formulated by You et al. (2014). The former gives a percentage of the harvest area of each crop in grid area, while the latter lists the average yield ( $\mathrm{t} / \mathrm{ha}$ ) of each crop in the grid. In this study, 12 crops are selected, basically covering the varieties in the Yellow River Basin. Among them, wheat and corn have a large planting area, accounting for $4.3 \%$ and $2.9 \%$ of the total area of eight provinces, respectively. The meteorological data are collected from the 121 meteorological stations of Chinese National Meteorological Bureau (Fig. 1). They are mainly used as input terms of CROPWAT software, including maximum and minimum temperature, wind speed, daylight hours, relative humidity and precipitation. The above kinds of data are based on the statistical information of 2017.

The irrigation area distribution map (Fig. 3) is obtained from the websit of FAO (http://www.fao.org/nr/water/aquastat/irrigationmap/index.stm). Irrigation facilities are concentrated in Shandong and Henan, between which irrigation facilities appear in more than $80 \%$ of Shandong (except central and southern region), and in more than $60 \%$ of Henan (except western region). The irrigated farmlands appear in a decentralized manner in Ningxia, Shanxi, Shaanxi and Gansu, and there are irrigated farmlands in the Yellow River irrigation area and Tongliao district in Inner Mongolia. Irrigated farmlands are scattered across the north side of the Yellow River Valley in eastern Qinghai. Regions with an irrigation ratio exceeding 70\% include Ningmeng irrigation area, Central Shaanxi Plain, Jinzhong, lower reach of Yellow River (Henan section) and areas in Shandong along Yellow River, which are commonly characterized by border on Yellow River, convenience for water intaking, superior agricultural natural conditions and development of irrigated agriculture. The ArcGIS 10.3 was employed to realize data calculation and visualization.

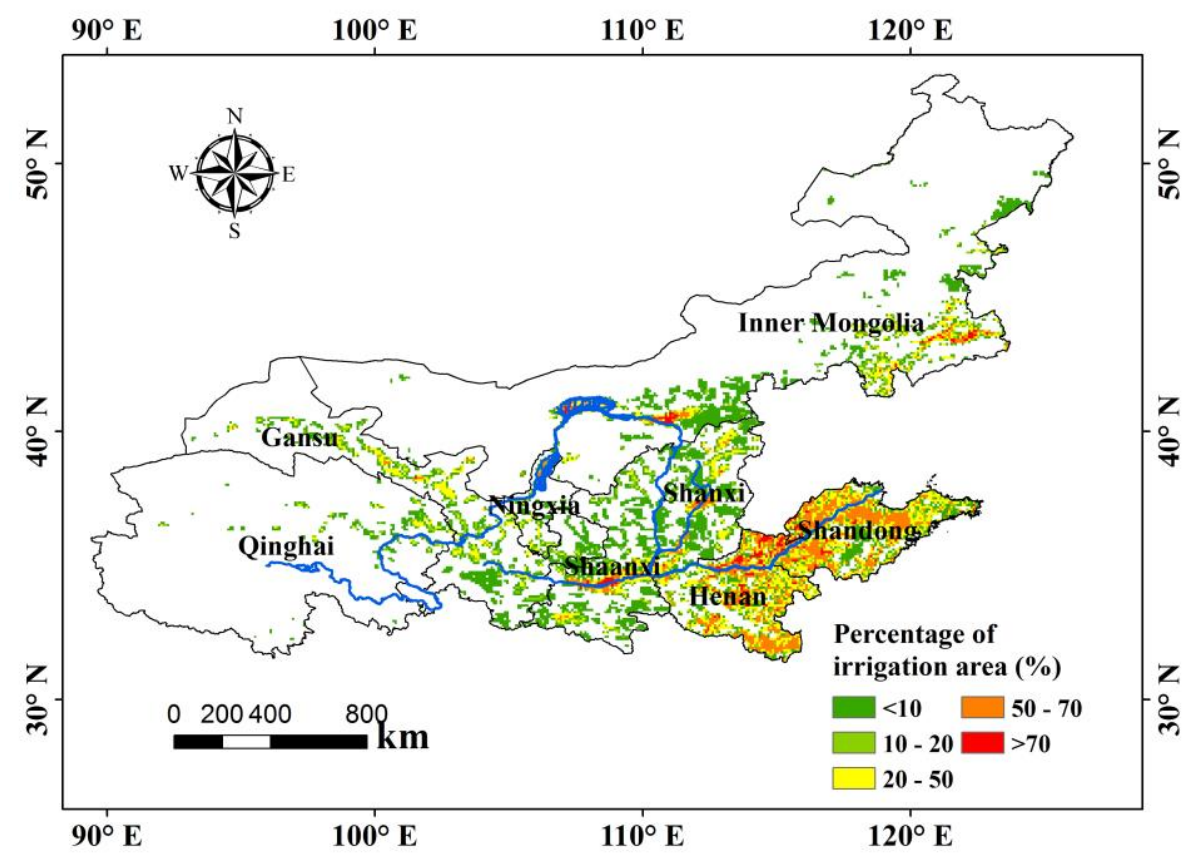

Figure 3. The percentage of irrigation area of the total agricultural land in 2017 


\section{Methodology}

\section{Crop water consumption}

The calculation steps of regional crop water consumption are as Equations 1-5:

$$
C W U=\sum_{c=1}^{12} C W U(c)
$$

where $c$ is the crop type, $C W U(c)$ is the regional water consumption of the $c$-th crop, with the unit of $\mathrm{m}^{3}$.

$$
C W U(c)=E T(c)
$$

The actual regional ET of the $c$-th crop ET(c) is calculated by Equation 3.

$$
E T(c)=E T_{g}(c)+E T_{b}(c)
$$

where $E T(c)_{g}$ and $E T(c)_{b}$ are respectively represent the green and blue water consumption of the $c$-th crop in the region. The blue water is the water resources of surface runoff and underground runoff. Then, the contribution rate of green water to the $c$-th crop's water consumption is:

$$
G W(c)=\frac{E T_{g}(c)}{C W U(c)}
$$

Contribution rate of green water in the region is calculated as:

$$
G W=\frac{\sum_{c=1}^{12} E T_{g}(c)}{\sum_{c=1}^{12} C W U(c)}
$$

\section{Green water consumption}

Crop evapotranspiration depends on crop water demand and soil water supply which comes from effective precipitation and irrigation. Here, a 5-arc minute resolution distribution map of irrigated farmland is selected. For Rain-fed Agricultural areas, effective precipitation is the only source of water available in soil, and evapotranspiration of crops is completely composed of green water. For irrigated areas, due to the lack of irrigation system data, it is assumed that irrigation water can meet crop water demand. Therefore, the transpiration of crops is the water demand of crops, in which the green water is supplied by effective precipitation and the blue water is supplied by irrigation water.

\section{Crop water demand}

When the blue and green water consumption of each crop in an area is analyzed, the crop water demand is first calculated at the observatory; then, Kriging interpolation is adopted to 
determine the crop water demand in each grid of this area; Later, according to the agricultural crop sown area distribution map and the irrigated area distribution map, the blue and green water consumption in each grid is obtained and then separately accumulated to finally get the blue and green water consumption of the crop in this area.

The crop water demand for a certain growth period $t$ is represented by $E T_{c}(c, t)$ which is calculated by Equation 6:

$$
E T_{c}(c, t)=K_{c}(c, t) \times E T_{0}(c, t)
$$

where $K_{c}(c, t)$ and $E T_{0}(c, t)$ are respectively represent the crop coefficient and the reference ET.

CROPWAT 8.0 is used to calculated crop water demand, effective precipitation and irrigation water demand. In CROPWAT, the $E T_{0}$ was calculated by Penman-Monteith formula (Allen et al., 1998). $K_{c}$ varies with crop growth stages, the $K_{c}$ values refer to http://www.fao.org/docrep/X0490E/x0490e0b.htm.

\section{Effective precipitation}

Effective precipitation is defined depending on different professional fields. Without a clear definition in agricultural production field, effective precipitation usually refers to part of precipitation that can meet the need for crop evapotranspiration, excluding surface runoff and deep seepage (Sikorska et al., 2018). In the CROPWAT software, there are four methods to calculate effective precipitation, namely the fixed ratio method, precipitation-based method, empirical formula method and USDA SCS method. Among them, the SCS method is the most widely used for agricultural water resources management. The SCS method is an empirical formula as Equation 7, which is deduced by analyzing precipitation data at 22 test stations for 50 years, and has been simplified to calculate the effective precipitation (Mishra and Singh, 2007).

$$
P_{e}= \begin{cases}P_{t} \times \frac{125-0.2 P_{t}}{125}, & P_{t}<250 \mathrm{~mm} \\ 125+0.1 \times P_{t}, & P_{t} \geq 250 \mathrm{~mm}\end{cases}
$$

where $P_{e}$ is effective precipitation, $\mathrm{mm} ; P_{t}$ is monthly precipitation, $\mathrm{mm}$.

\section{Green water consumption in grids}

Taking 10 days as the calculation period, the green water consumption $E T_{g}(c, i, t)$ of the $c$-th crop in the No. $i$ grid is determined by the crop water requirement $E T_{c}(c, i, t)$ and effective precipitation $P_{\varepsilon}(c, i, t)$ in the period $t$, through Equation 8:

$$
E T_{\mathrm{g}}(c, i, t)=\min \left[E T_{c}(c, i, t), P_{e}(c, i, t)\right]
$$

Irrigation water requirement $\operatorname{IRR}(c, i, t)$ during period $t$ is calculated by Equation 9:

$$
\operatorname{IRR}(c, i, t)=E T_{c}(c, i, t),-E T_{\mathrm{g}}(c, i, t)
$$


That is the amount of blue water is by $(E q .10)$ :

$$
E T_{b}(c, i, t)=\operatorname{IRR}(c, i, t)
$$

During the whole growth period, the amount of green water focr the $c$-th crop on the $i$-th grid is:

$$
E T_{\mathrm{g}}(c, i)=\sum_{t} E T_{g}(c, i, t)
$$

During the whole growth period, the amount of blue water for the $c$-th crop on the $i$ th grid is:

$$
E T_{b_{\mathrm{g}}}(c, i)=\sum_{t} E T_{b}(c, i, t)
$$

\section{Regional green water consumption}

The regional green water consumption of the $c$-th crop $E T_{g}(c)$ is calculated by Equation 13:

$$
E T_{g}(c)=\sum_{i}\left[E T_{g}(c, i) \times A(c, i)\right]
$$

where the $A(c, i)$ is the planting area percentage of the $c$-th crop on the $i$-th grid.

The regional blue water consumption of the $c$-th crop $E T_{b}(c)$ is obtained through Equation 14:

$$
E T_{b}(c)=\sum_{i}\left[E T_{b}(c, i) \times A(c, i) \times I(c, i)\right]
$$

where the $I(c, i)$ is the irrigation area percentage of the $c$-th crop on the $i$-th grid.

\section{Agricultural water footprint}

The agricultural water footprint includes blue water and green water. The primary industry water footprint refers only to blue water. Some water consumed by crops flows out of the area, and some is used by local residents. The rest is the agricultural water footprint. Thus, calculation of agricultural water footprint is based on the primary industry water footprint and crop water consumption, and the total water consumed by the primary industry is composed of the water footprint of the primary industry and the primary industry net output virtual water. Considering that the Yellow River Basin is an important agricultural base, it is assumed that the net output virtual water of agriculture does not flow in but flow out. Then, the crop water consumption is equal to the amount of the agricultural water footprint and the net output. Thus, the proportion of the agricultural water footprint to the crop water consumption is equal to the proportion of the primary industry water footprint to the primary industry water. The agricultural water footprint can be calculated as shown in Equation 15: 


$$
W F P_{a g r}=C W U \times \frac{W F P_{f i r}}{W F P_{f i r}-E W F P_{f i r}}
$$

where $W F P_{a g r}$ is agricultural water footprint, $\mathrm{m}^{3} ; W F P_{f i r}$ is water footprint of primary industry, $\mathrm{m}^{3} ; E W F P_{f i r}$ is external water footprint of primary industry, $\mathrm{m}^{3}$. $W F P_{f i r}$ and $E W F P_{\text {fir }}$ are calculated by input-output method according to the reference (Yin et al., 2016).

\section{Crop water consumption coefficient}

The crop water consumption coefficient refers to the water consumed per unit of yield, which is the ratio of crop water consumption to the yield. It is an important indicator to measure the water consumption efficiency in crop production. Here, the crop water consumption of each grid is obtained with the above method, and the yield data adopts a crop yield distribution map with 50-arc resolution. The water consumption coefficient calculation processes are Equations 16-18:

$$
W C C(c, i)=E T(c, i) / Y(c, i)
$$

where $W C C(c, i)$ is the water consumption coefficient of the $c$-th crop on the $i$-th grid, and $Y(c, i)$ is the yield of the $c$-th crop on the $i$-th grid.

$$
W C C(c)=\sum_{i}[E T(c, i)] / \sum_{i}[Y(c, i)]
$$

where $W C C(c)$ is the water consumption coefficient of the $c$-th crop cin the area.

$$
W C C=\frac{\sum_{c=1}^{12} \sum_{i} E T(c, i)}{\sum_{c=1}^{12} \sum_{i} Y(c, i)}
$$

where $W C C$ is the agricultural water consumption coefficient in the area.

\section{Results}

\section{Distribution of crop water consumption}

We can see from Figure 4 that similar to the precipitation contour, crop water consumption in the Yellow River Basin roughly tends to descend to zero from southeast to northwest, and local areas are affected by irrigation. Areas with high water consumption are closely related to irrigation facilities. The irrigation areas account for a large proportion in total irrigation districts along Yellow River, and the crop water consumption per unit area is also large. Crop water consumption has the maximum value in the areas with an irrigation area exceeding $70 \%$, in which the crop water demand can be fully met and the multiple index and the planting density of crops are 
high. Especially in Shandong and central and eastern Henan, the water consumption in the grid basically exceeds more than 10 million $\mathrm{m}^{3}$ per year.

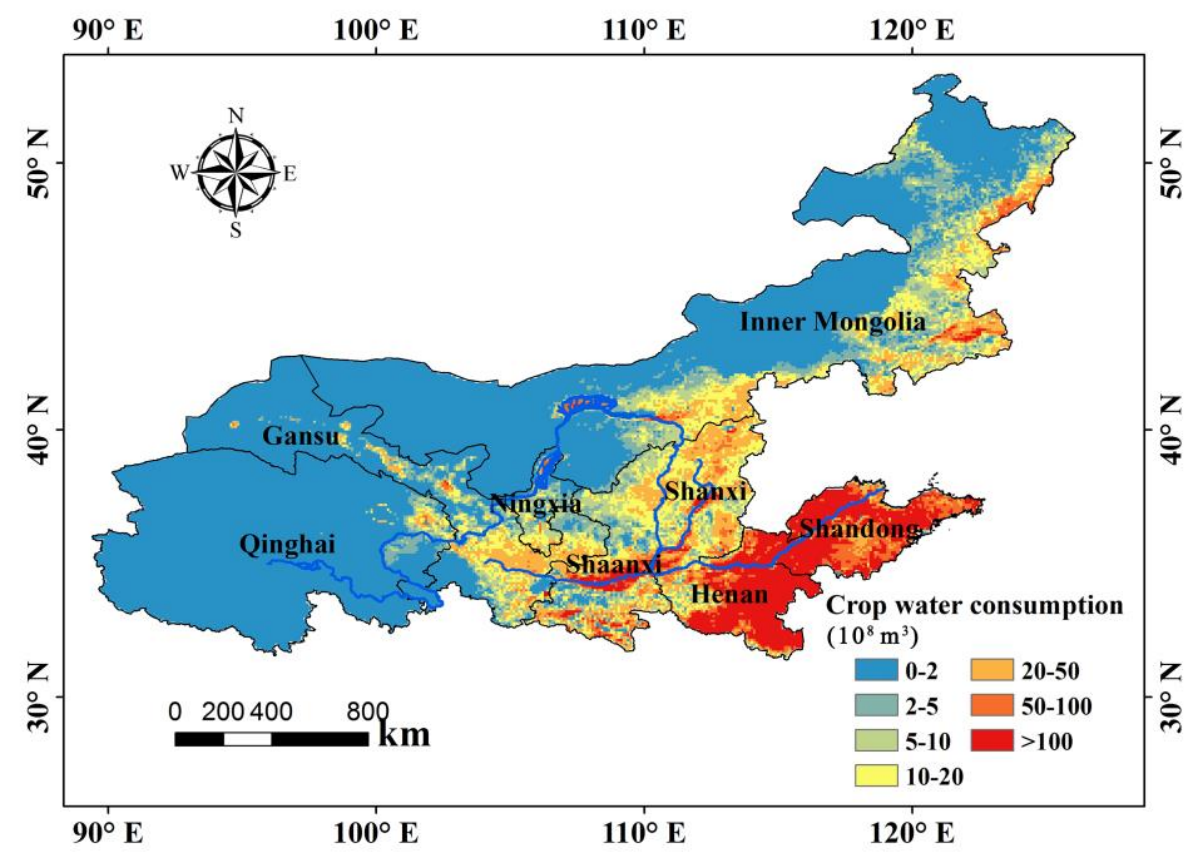

Figure 4. Spatial distribution of crop water consumption in 5 arc-minutes grid $\left(10^{5} \mathrm{~m}^{3} /\right.$ a $)$

The entire range of Ningxia, Shanxi and Shaanxi, most part of Gansu and southeastern Inner Mongolia are basically covered by crop water consumption, as the proportion of irrigation areas in those regions are low and the agriculture is mostly rainfed. Except for the irrigated regions along Yellow River, the water consumption per unit area keeps basically less than 5 million $\mathrm{m}^{3}$ per year in those regions, followed by regions along the northwest of which the water consumption per unit area is less than 1 million $\mathrm{m}^{3}$ (roughly $150 \mathrm{~m}^{3} / \mathrm{ha}$ ). The eastern valley in Qinghai Province is the area with small water consumption per unit area.

As far as crop water consumption is concerned (Fig. 5), corn and wheat are major crops that consume $31 \%$ and $29 \%$ of total crop water consumption, followed by cotton and soybeans, which both consume $9 \%$ of total water.

It can be seen from Table 1, the crop water consumption in the Yellow River Basin in 2017 was 84.25 billion $\mathrm{m}^{3}$. Henan and Shandong are at the top $(36.1 \%$ and $30.0 \%$ respectively). Consistent with the above, the crop planting area is large in both provinces, and the water consumed per unit area is large. Inner Mongolia and Shaanxi are the next (respectively $11.1 \%$ and $10.1 \%$ ), followed by Qinghai and Ningxia $(0.5 \%$ and $1.1 \%$ respectively).

\section{Agricultural water footprint}

The agricultural water footprint of the Yellow River Basin amounts to 49.45 billion $\mathrm{m}^{3}$ (Table 2), which is mainly caused by food production and is greatly related to the population. Henan tops the water footprint of the Yellow River Basin by 29.93 billion $\mathrm{m}^{3}$ and Qinghai is at the bottom at 480 million $\mathrm{m}^{3}$. The proportion of 
agricultural water footprint to crop water consumption explains the proportion of local food water consumption to the local water consumption, compared to 0.587 in the basin. Henan and Gansu are among the largest to 0.985 and 0.980 respectively. The food produced in these two provinces is basically self-consumed.

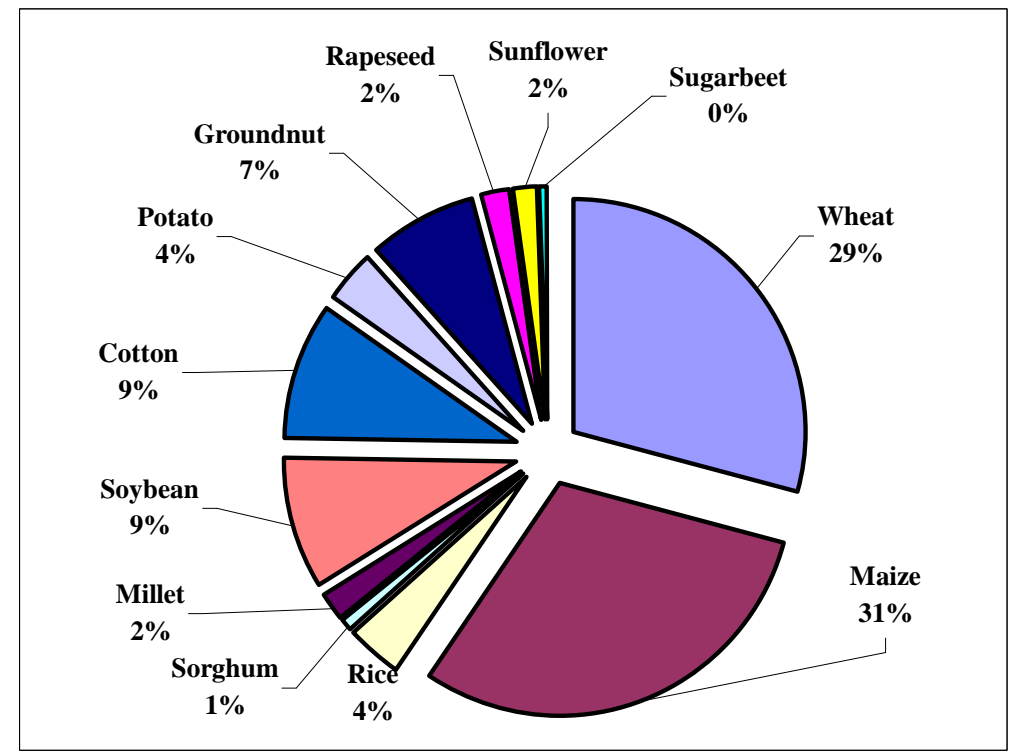

Figure 5. Percentage of crop water consumption per crop

Table 1. Crop water consumption and composition of provinces and autonomous regions in the Yellow River Basin

\begin{tabular}{|c|c|c|c|c|c|}
\hline \multirow[b]{2}{*}{ Province } & \multicolumn{3}{|c|}{ Crop water consumption $\left(10^{8} \mathrm{~m}^{3}\right)$} & \multirow{2}{*}{$\begin{array}{c}\text { Percentage of green } \\
\text { water }(\%)\end{array}$} & \multirow{2}{*}{$\begin{array}{c}\text { Percentage of crop } \\
\text { water consumption in } \\
\text { each province }(\%)\end{array}$} \\
\hline & $\begin{array}{l}\text { Green } \\
\text { water }\end{array}$ & Blue water & Total & & \\
\hline Qinghai & 4.1 & 0.4 & 4.5 & 90.3 & 0.5 \\
\hline Gansu & 26.7 & 5.3 & 32.0 & 83.5 & 3.8 \\
\hline Ningxia & 5.0 & 4.2 & 9.2 & 54.5 & 1.1 \\
\hline Inner Mongolia & 77.7 & 15.1 & 92.8 & 83.7 & 11.0 \\
\hline Shaanxi & 69.8 & 14.9 & 84.7 & 82.4 & 10.1 \\
\hline Shanxi & 52.0 & 10.8 & 62.8 & 82.7 & 7.5 \\
\hline Henan & 240.6 & 63.4 & 303.9 & 79.1 & 36.1 \\
\hline Shandong & 186.9 & 65.6 & 252.5 & 74.0 & 30.0 \\
\hline Total & 662.7 & 179.7 & 842.5 & 78.7 & 100.0 \\
\hline
\end{tabular}

The primary industry water footprint is all blue water. Difference with the agricultural blue water footprint lies that: firstly, the blue water footprint is the crop water consumption, while the primary industry water footprint contains irrigation losses; secondly, the blue water footprint is direct water consumption, but the primary industry water footprint contains indirect water consumption; thirdly, agriculture, forestry, animal husbandry and fishery industries are involved in the primary industry water footprint. 
Table 2. Water footprint of provinces and areas in the Yellow River Basin

\begin{tabular}{c|c|c|c|c|c}
\hline \multirow{2}{*}{ Province } & \multirow{2}{*}{$\begin{array}{c}\text { Ratio of agricultural water } \\
\text { footprint to crop water } \\
\text { consumption }\end{array}$} & $\begin{array}{c}\text { Agricultural } \\
\text { water } \\
\text { footprint }\end{array}$ & $\begin{array}{c}\text { Green } \\
\text { water } \\
\text { footprint }\end{array}$ & $\begin{array}{c}\text { Blue } \\
\text { water } \\
\text { footprint }\end{array}$ & $\begin{array}{c}\text { Primary } \\
\text { industry water } \\
\text { footprint }\end{array}$ \\
\hline Qinghai & 1.068 & 4.8 & 4.3 & 0.5 & 36.7 \\
Gansu & 0.980 & 31.3 & 26.2 & 5.2 & 66.4 \\
Ningxia & 0.644 & 5.9 & 3.2 & 2.7 & 31.9 \\
Inner Mongolia & 0.106 & 9.8 & 8.2 & 1.6 & 26.2 \\
Shaanxi & 0.673 & 57.0 & 47.0 & 10.0 & 14.6 \\
Shanxi & 1.020 & 64.0 & 53.0 & 11.0 & 51.4 \\
Henan & 0.985 & 299.3 & 236.9 & 62.4 & 98.9 \\
Shandong & 0.697 & 176.1 & 130.3 & 45.8 & 72.4 \\
Total & 0.587 & 494.5 & 389.0 & 105.5 & 398.4 \\
\hline
\end{tabular}

\section{Green water consumption}

As shown in Table 1, the green water consumption accounted for $78.7 \%$ of the crop water consumption in the Yellow River Basin, falling within the world average $75 \%$ $81 \%$ caused by different research methods. Among 8 provinces, Qinghai consumes the most water with a percentage of $90.3 \%$, followed by Inner Mongolia, Gansu, Shanxi and Shaanxi, of which the green water consumption percentage is close and measured between 82 and $84 \%$. The third are Henan and Shandong with a percentage of $79.1 \%$ and $74.0 \%$, respectively. The bottom one is Ningxia with a percentage of $54.5 \%$. Obviously, in areas with more developed irrigated agriculture and high blue water utilization volume, the utilization rate of green water consumption is relatively low. Ningxia especially falls behind the other provinces in green water utilization rate, probably because of backward irrigation practice and the low water consumption efficiency. In addition, when the green water can meet the growth demand, unnecessary irrigation results in unnecessary wastage of water resources, and a decrease in the proportion of green water consumption.

Consistent with the distribution of water consumption (as shown in Fig. 6), the spatial distribution green water consumption in the Yellow River Basin tends to descent from southeast to northwest, partially affected by irrigation. In other words, the utilization volume of green water is related to the agricultural development intensity. In areas with developed agriculture, planting more corps lead to higher green water consumption. Relatively speaking, as the southeast is a natural and suitable area for agriculture owing to abundant precipitation, the agricultural is relatively highly developed. In the Ningmeng Irrigation Region in the northwest, Central Shaanxi Plain and Jinzhong, it is easy to draw the Yellow River water for agricultural irrigation purpose, although there is no abundant precipitation. The green water consumption in the above areas is correspondingly large.

The proportion of green water to crop water consumption reflects the extent to which natural water resources are used in agriculture. As shown in Figure 7, the percentage of green water consumption is mostly greater than $95 \%$ in the Yellow River Basin, dominated by rainfed agriculture. Except for several regions, the proportion of Ningmeng Irrigation Region, Central Shaanxi Plain, Jinzhong and East Inner Mongolia 
Irrigation Region and the western Gansu are among the lowest in green water consumption to below $50 \%$, followed by the northwest of Shanxi and the north of Henan at $50 \%$ to $70 \%$. Among these areas, except for the western Gansu, the irrigation density is high in other areas; the proportion of green water consumption in western Gansu is smaller because of scarce precipitation and strong evaporation, and less effective precipitation available to crops.

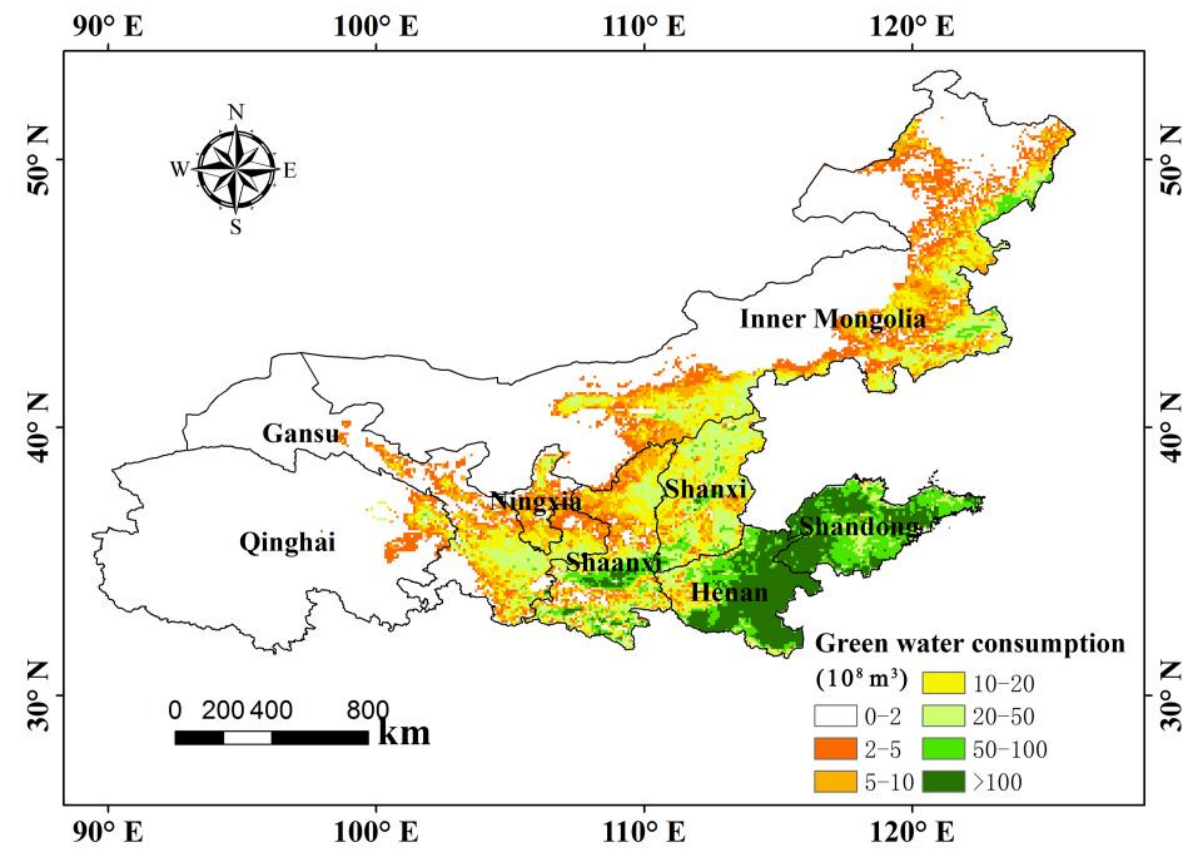

Figure 6. Spatial distribution of crop green water consumption in arc-minutes grid $\left(10^{5} \mathrm{~m}^{3}\right)$

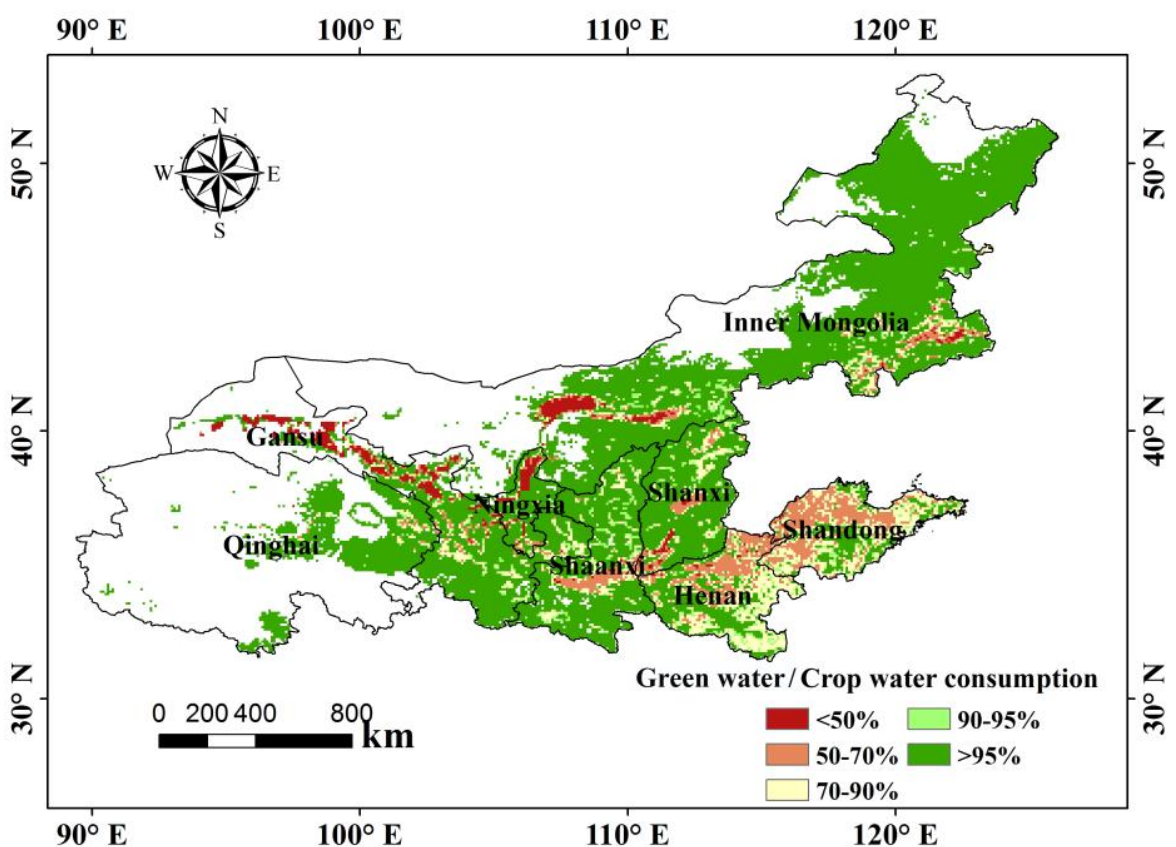

Figure 7. The percentage of green water consumption to crop water consumption 
As shown in Figure 8, among the 12 crops, the rapeseed consume the most water with a percentage of $98 \%$, and wheat and sugar beet consume the least water with a percentage of $58 \%$ and $66 \%$ respectively. The other crops account for 80 to $95 \%$ of water consumption. Wheat and corn are two crops with the largest planting area and water consumption in the Yellow River Basin, between which corn generally grows in rainy and hot season and its demand for water can be basically met by natural precipitation. On the contrary, in the critical growth period of wheat, the irrigation practice is required due to less precipitation. The wheat accounts for $29 \%$ of the total water consumption in the basin. According to the $74.1 \%$ percentage of green water consumption to crop water consumption in the basin, it can be concluded that the wheat accounts for $56 \%$ of the blue water consumption of the basin.

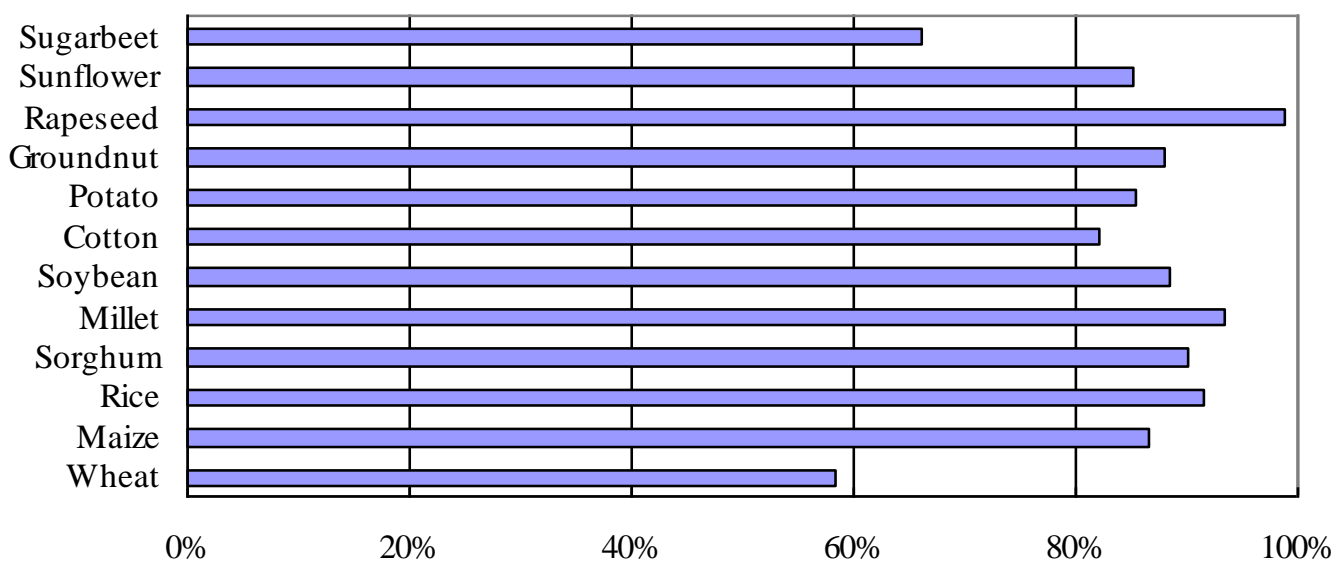

Figure 8. The percentage of green water in crop water

\section{Crop water consumption coefficient}

The crop water consumption coefficient refers to the water consumption per specific yield. Similar to the total water input coefficient defined in the water footprint (water consumption per specific yield), this coefficient can denote the crop water efficiency. The difference is that the total water input coefficient targets at withdrawals of blue water, including blue water consumption and recovery amount; however, the crop water consumption coefficient includes the portion of blue water that is consumed by the crops and the green water. As shown in Figure 9, the water consumption coefficient lies between $0.4-1.0 \mathrm{~m}^{3} / \mathrm{kg}$ for most areas. The water consumption coefficient is high in the southern part of the basin, and is low in western Gansu, northern Ningxia (excluding the Yellow River irrigation area), and central and southern Shandong. The low coefficient of western Gansu is caused by the low water consumption. This region has sufficient sunshine, which is conducive to crop growth, and keeps up certain production even if the water demand cannot be met. The central part of Shandong is a mountainous area with relatively underdeveloped irrigation facilities. Irrigation is to achieve output at the cost of water resources, and cannot significantly increase the crop water consumption coefficient.

The crop water consumption coefficient of the basin is $0.622 \mathrm{~m}^{3} / \mathrm{kg}$, as shown in Figure 10. Those eight provinces can be divided by the crop water consumption coefficient into three levels: Ningxia, Gansu and Qinghai are at the bottom (less than $0.5 \mathrm{~m}^{3} / \mathrm{kg}$ ) at $0.400 \mathrm{~m} 3 / \mathrm{kg}, 0.427 \mathrm{~m}^{3} / \mathrm{kg}$ and $0.430 \mathrm{~m}^{3} / \mathrm{kg}$, respectively, followed by 
Inner Mongolia, Shandong and Shanxi (basically $0.5-0.6 \mathrm{~m}^{3} / \mathrm{kg}$ ) measured $0.536 \mathrm{~m}^{3} / \mathrm{kg}$ and $0.562 \mathrm{~m}^{3} / \mathrm{kg}$ respectively. Shaanxi and Henan are at the top at $0.754 \mathrm{~m}^{3} / \mathrm{kg}$ and $0.748 \mathrm{~m}^{3} / \mathrm{kg}$, respectively. For the entire basin, the level of agricultural production is highest in Henan and Shandong and lowest in Qinghai. Therefore, the current crop water consumption coefficient of the Yellow River Basin has no obvious relationship with the agricultural production level.

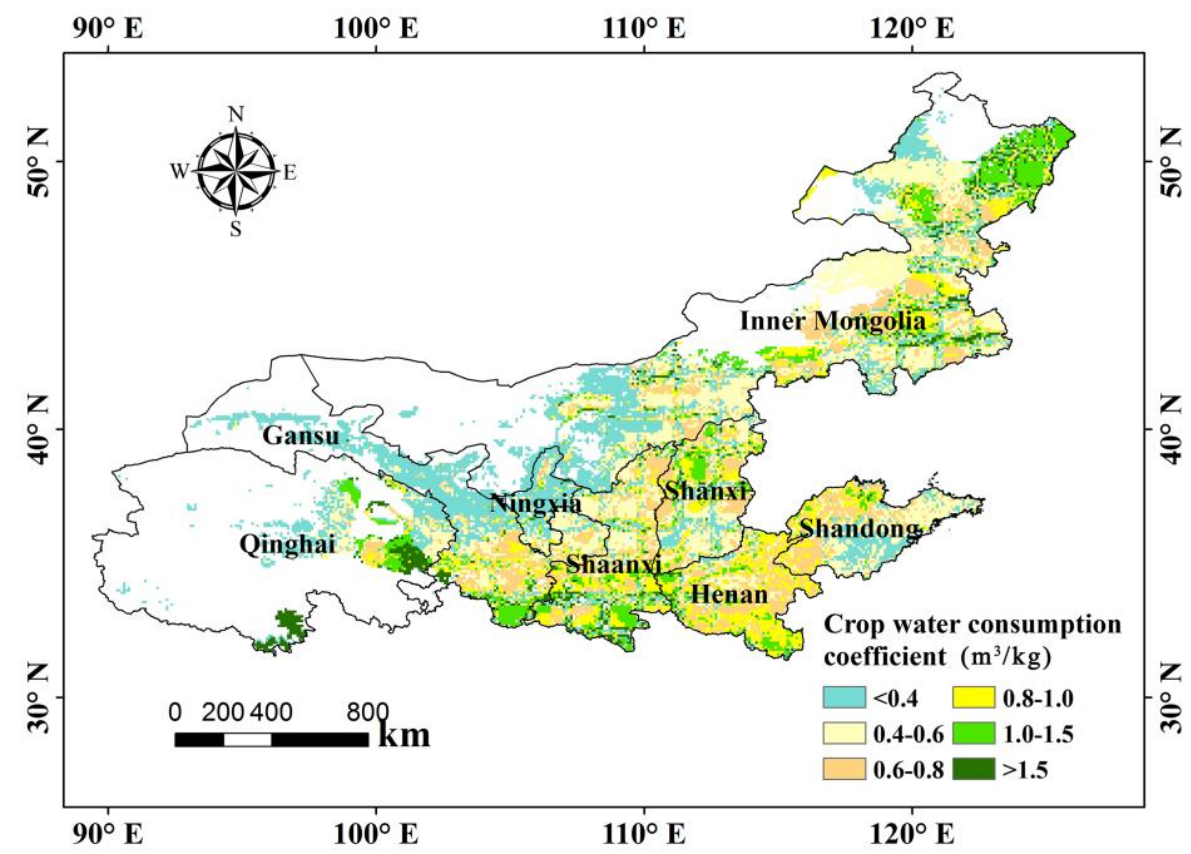

Figure 9. The spatial distribution of crop water consumption coefficient

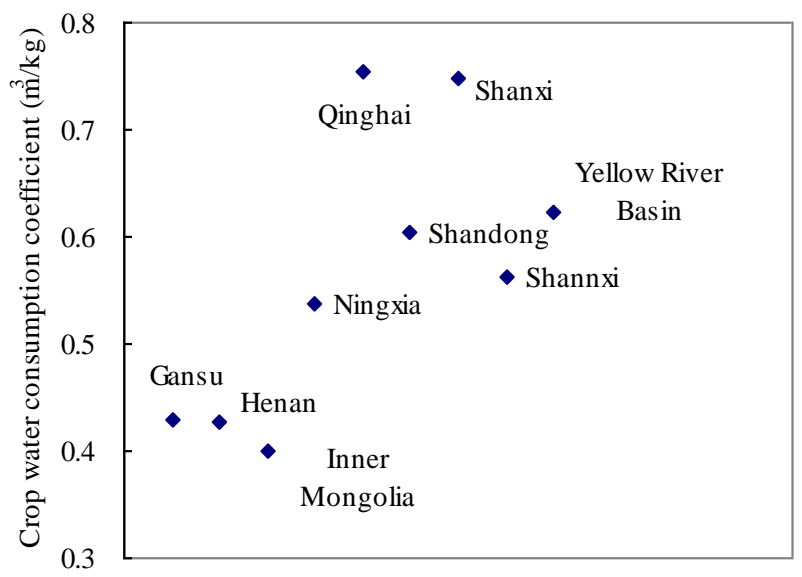

Figure 10. Crop water consumption coefficient in each province

For different crops, the water consumption coefficient is mainly related to crop characteristics. In the basin, sugar beet and potato consume the least water with a coefficient measured $0.118 \mathrm{~m}^{3} / \mathrm{kg}$ and $0.150 \mathrm{~m}^{3} / \mathrm{kg}$, respectively. Cotton consumes the most water with a coefficient of $1.846 \mathrm{~m}^{3} / \mathrm{kg}$ (as shown in Fig. 11). Sugar beet and 
potato have a high density of harvested products because tubers are harvested, while the cotton is low-density in the harvested product because fiber is harvested. The water consumption coefficient is almost the same among cereals, wheat, corn, sorghum and rice, close to oil crops. The water consumption coefficient of broomcorn millet is large mainly because of low yield of these two crops.

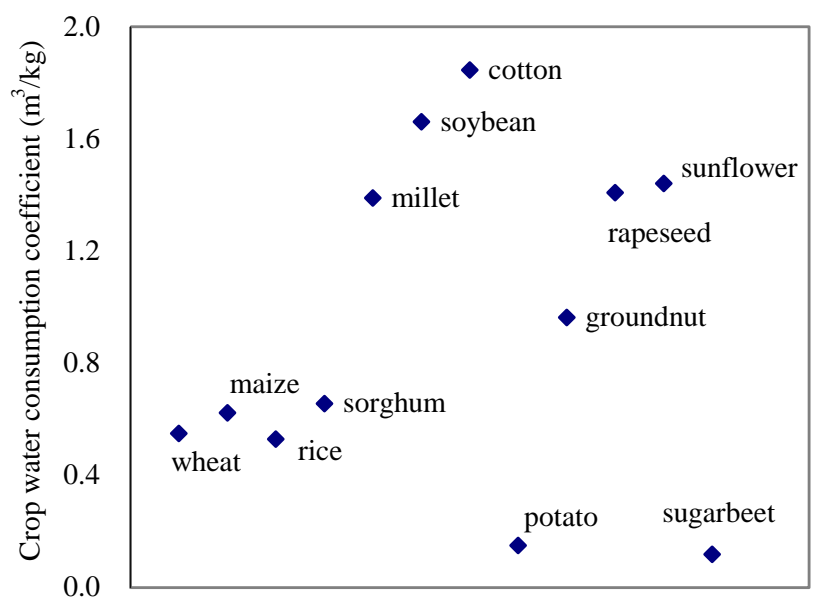

Figure 11. Crop water consumption coefficient for different crop types

\section{Distribution of wheat's water consumption}

Wheat is the crop in the Yellow River Basin (Table 3) with the largest planting area. As described earlier, the blue water consumed accounts for $56 \%$ of the total water consumption in the basin, mainly for wheat production. Understanding the water consumption characteristics of wheat, especially distribution of blue water, helps to propose measures of improving the wheat's water consumption efficiency and will have a significant effect on reducing agricultural water consumption throughout the basin.

Firstly, by analyzing wheat's overall water consumption and yield in all provinces/regions of the basin, we can see that the characteristic is obvious that wheat's water consumption is mainly confined to Henan and Shandong, as shown in Table 3. Henan is at the top, with 10.13 billion $\mathrm{m}^{3}$ of wheat's water consumption, followed by Shandong with 7.70 billion $\mathrm{m}^{3}$. Both provinces take up $72.8 \%$ of the total water consumed in the basin. Henan and Shandong also consume most of blue water, respectively 4.06 billion $\mathrm{m}^{3}$ and 3.86 billion $\mathrm{m}^{3}$, accounting for $39.8 \%$ and $37.9 \%$ of the total blue water consumption in the basin. Both provinces are equal in wheat yield and are the largest contributors in the basin for wheat, both accounting for $36.4 \%$ of the total wheat yield in the basin.

For the wheat's water consumption coefficient, Qinghai is at the lowest point to $0.350 \mathrm{~m}^{3} / \mathrm{kg}$, mainly because there are few irrigation facilities in the province featured with basically rainfed agriculture and the small water consumption. It is similar with Gansu to this point. For other provinces, the water consumption coefficient depends mainly on the agricultural water productivity. Shaanxi is at the top to $0.704 \mathrm{~m}^{3} / \mathrm{kg}$, and the agricultural water productivity is low. The water consumption coefficient of Henan is above the average, and its agricultural water productivity is also low. The water consumption coefficient of Shandong is under the average. 
Table 3. Water consumption of wheat in provinces of the Yellow River Basin

\begin{tabular}{|c|c|c|c|c|c|c|c|}
\hline \multirow{2}{*}{ Province } & \multicolumn{3}{|c|}{$\begin{array}{c}\text { Water consumption }\left(10^{8}\right. \\
\left.\mathbf{m}^{3}\right)\end{array}$} & \multirow{2}{*}{$\begin{array}{l}\text { Yield } \\
\left(10^{9} \mathrm{~kg}\right)\end{array}$} & \multirow{2}{*}{$\begin{array}{c}\text { Water } \\
\text { consumption } \\
\text { coefficient }\left(\mathrm{m}^{3} / \mathrm{kg}\right)\end{array}$} & \multirow{2}{*}{$\begin{array}{c}\text { Green } \\
\text { water/total } \\
(\%)\end{array}$} & \multirow{2}{*}{$\begin{array}{c}\text { Blue water } \\
\text { consumption } \\
\text { proportion (\%) }\end{array}$} \\
\hline & $\begin{array}{l}\text { Green } \\
\text { water }\end{array}$ & $\begin{array}{l}\text { Blue } \\
\text { water }\end{array}$ & $\begin{array}{l}\text { Total } \\
\text { value }\end{array}$ & & & & \\
\hline Qinghai & 1.6 & 0.3 & 1.9 & 0.5 & 0.350 & 84.2 & 0.3 \\
\hline Gansu & 9.8 & 2.7 & 12.5 & 2.7 & 0.462 & 78.4 & 2.6 \\
\hline Ningxia & 1.3 & 1.5 & 2.8 & 0.6 & 0.466 & 46.4 & 1.4 \\
\hline Inner Mongolia & 11.0 & 4.2 & 15.2 & 2.7 & 0.557 & 72.4 & 4.1 \\
\hline Shaanxi & 13.2 & 9.2 & 22.4 & 3.2 & 0.704 & 58.9 & 9.0 \\
\hline Shanxi & 6.8 & 4.8 & 11.6 & 2.4 & 0.488 & 58.6 & 4.8 \\
\hline Henan & 60.7 & 40.6 & 101.3 & 16.2 & 0.625 & 59.9 & 39.8 \\
\hline Shandong & 38.4 & 38.6 & 77.0 & 16.2 & 0.476 & 49.9 & 37.9 \\
\hline Total & 142.8 & 101.9 & 244.7 & 44.55 & 0.549 & 58.4 & 100.0 \\
\hline
\end{tabular}

By comparing the proportion of green and blue water consumption in wheat's water consumption (Fig. 12), the spatial distribution of wheat's water consumption in each province of the basin is analyzed.

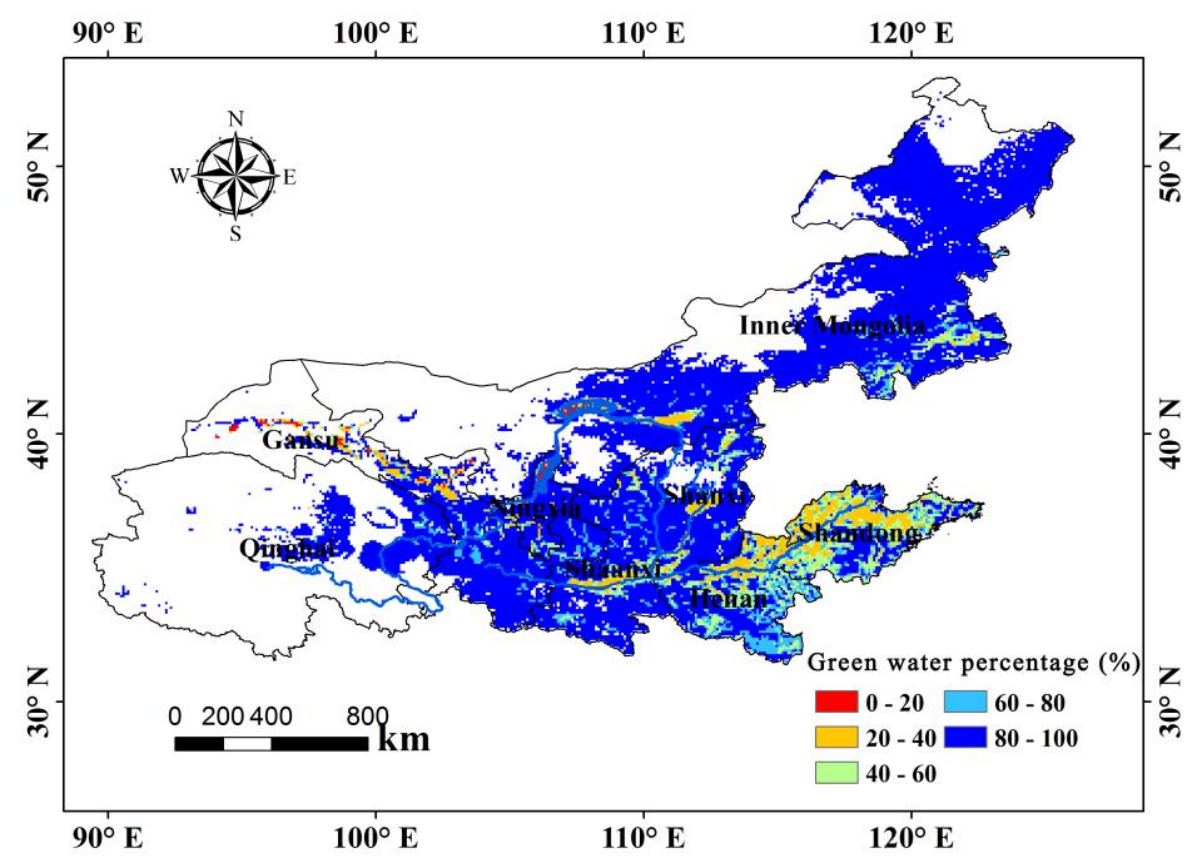

Figure 12. The percentage of green water to total water consumption in wheat

Wheat is widely cultivated in the basin, and the distribution of blue water consumption is consistent with that of irrigation facilities. As the largest blue water consumption per unit area is primarily centered on most areas of Henan and Shandong, and Central Shaanxi Plain, the wheat's irrigating water consumption in these three provinces is relatively large. Correspondingly, a bigger green water consumption corresponds to a smaller green water consumption. The spatial distribution of proportion of wheat's 
green water consumption in wheat water consumption is similar to population distribution of all crops in the basin (Fig. 13). The proportion is bigger than $80 \%$ for most of planting areas, compared to $20-\%$ of Ningmeng irrigation region which is at the bottom one. From this point, it can also be proved that wheat is the main waterconsuming crop in the basin, and its distribution has a greater impact on the population distribution of water consumption in the basin. Correspondingly, in Shandong, Henan, Central Shaanxi Plain, Ningmeng irrigation region, etc., according to the law of crop water demand, making full use of green water can effectively reduce the amount of irrigating water consumed, when guaranteeing the yield.

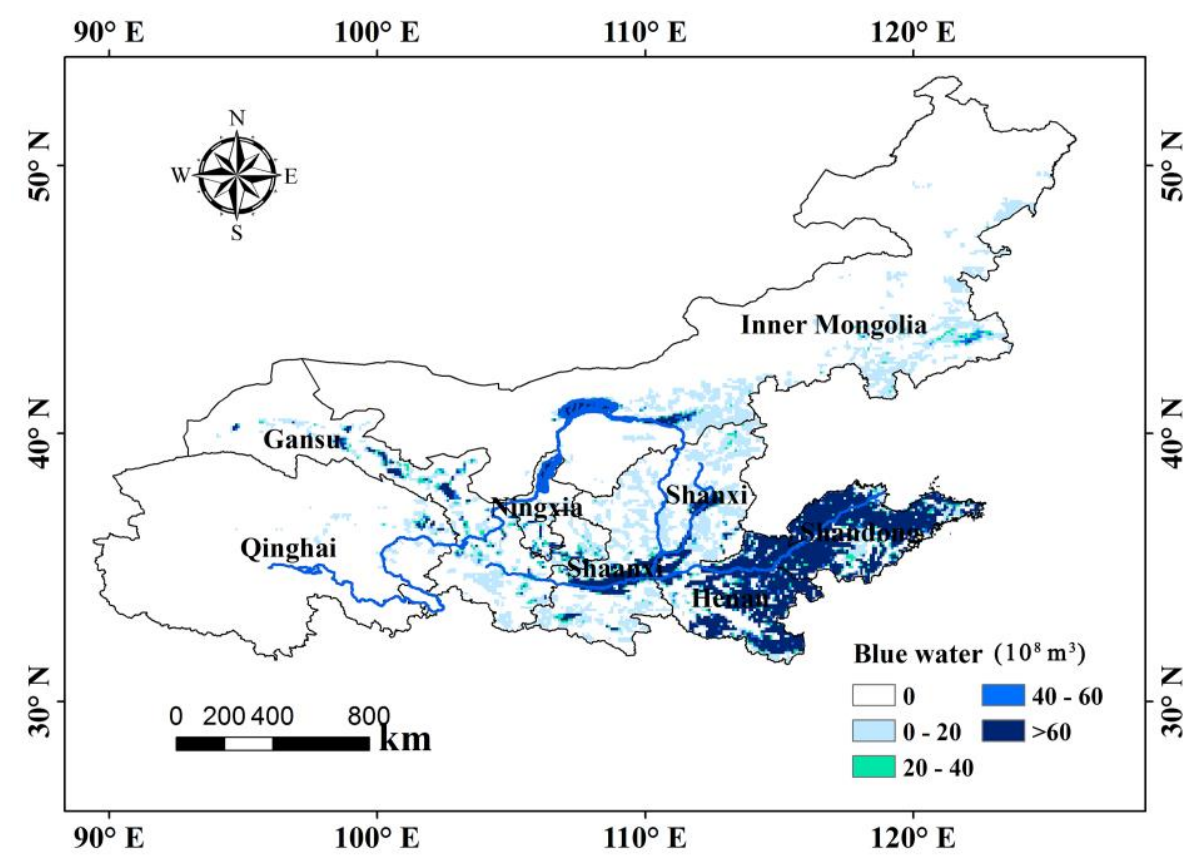

Figure 13. The spatial distribution of wheat blue water consumption in the 5 arc-minutes grid $\left(10^{5} \mathrm{~m}^{3}\right)$

\section{Conclusions and discussion}

In this study, rainfed and irrigated farmlands are divided according to the irrigation area distribution map, and 12 major crops in the basin are selected as objects. According to crop water demand and effective precipitation, the method of calculating regional crop water consumption and agricultural water footprint is proposed to study the situation of the Yellow River Basin. The main conclusions are as follows:

(1) Similar to precipitation contour, distribution of crop water consumption in the Yellow River Basin tends to descend from southeast to northwest. Local areas are affected by irrigation. High value areas are mainly irrigation regions along the Yellow River and the others have small water consumption due to rainfed agriculture. In the Yellow River Basin, the agricultural water consumption in 2017 was 84.25 billion $\mathrm{m}^{3}$. Henan and Shandong take up $66 \%$ of the total water consumption, and the wheat and corn take up $60 \%$ of the total water consumption.

(2) The proportion of green water consumed in the Yellow River Basin is $78.7 \%$, which is around the global average. The spatial distribution of crop green water 
consumption generally conforms to the water consumption distribution. In areas with high water consumption, the amount of green water consumed increases because the agriculture is developed and there are more crops planted. As for most of rainfed agriculture -based areas in Yellow River Basin, green water consumption accounts for $95+\%$ of crop water consumption. The lower values are in areas with well-developed irrigated agriculture, and in western Gansu due to less precipitation, strong evaporation, and less available effective precipitation for crops. In the irrigation areas, unnecessary irrigation can reduce the green water consumption.

(3) The agricultural water footprint is 52 billion $\mathrm{m}^{3}$ in the Yellow River Basin, in which Henan is at the top at 29.93 billion $\mathrm{m}^{3}$ and Qinghai is at the bottom at 480 million $\mathrm{m}^{3}$. The largest in Henan is $\mathrm{m}^{3}$, and the minimum in $\mathrm{s} 480$ million $\mathrm{m}^{3}$. Agricultural water footprint accounts for 0.587 of crop water consumption. Henan and Gansu are at the top respectively at 0.985 and 0.980 , indicating that the grain produced by these two provinces is basically used for themselves.

(4) The proportion of green water consumption is mostly higher than $80 \%$. Wheat is required for water irrigation because the rain season does not move in line with hightemperature season during its growth duration. Its green water consumption accounts for $58 \%$ of the total water consumed during the growth period. In addition, wheat consumes $56 \%$ of the total blue water consumed by crops in the basin.

(5) The crop water consumption coefficient reflects the water utilization level. The average water consumption coefficient is $0.622 \mathrm{~m}^{3} / \mathrm{kg}$ for the Yellow River Basin, in which most of areas fall between $0.4-1.0 \mathrm{~m}^{3} / \mathrm{kg}$. Ningxia, Gansu and Qinghai have the low water consumption coefficient, among which western Gansu, northern Ningxia (excluding the irrigation areas along Yellow River) and central and southern Shandong are among the lowest. The crop water consumption coefficient of the Yellow River Basin has no obvious relationship with the agricultural production level, and the irrigation cannot enhance the coefficient. For different crops, the water consumption coefficient is mainly related to the crop characteristics, and the water consumption coefficient of the tuberiferous crops is the largest.

In Rain-fed Agricultural areas, green water absorptivity is closely related to crop yield. Raising the utilization rate of green water in irrigated agricultural areas can reduce irrigation water use. The reason lies not in the low precipitation, but in the uneven distribution of precipitation, which is not consistent with the period of crop water demand. The total amount of water for crops is sufficient, but not at the right time.

Making full use of green water can start from two aspects. One is to increase the storage of green water through various measures, including deep tillage, mulching and other field management means to promote precipitation infiltration, reduce soil evaporation; and terraces in mountainous areas, rainwater collection and other facilities. Secondly, in view of irrigated agriculture, we should understand the distribution law of precipitation, the dynamics of soil moisture and the law of crop water demand, and supplement irrigation under the premise of insufficient green water.

Proportion of green water consumption to water consumption depends mainly on the volume of irrigating water. The green water consumption is negatively related to the irrigation amount. Ningxia is at the bottom, followed by Shandong. Both provinces rely too much on irrigating water and do not make full use of green water.

Irrigated area is one of the main factors of water footprint growth, so it is imperative to restrict the development of irrigation area. This refers to the traditional irrigated 
farmland. Irrigation is an important guarantee for grain production in the basin. The effect of water saving irrigation on increasing income has been widely recognized and still needs to be vigorously implemented. In addition, improving the effective utilization rate of irrigation water are mainly aimed at the existing problems. Firstly, the irrigation facilities should be renovated to reduce the waste of water resources; secondly, the traditional surface irrigation methods should be changed and furrow irrigation should be adopted to improve the utilization rate of irrigation water; thirdly, a reasonable irrigation system should be established to improve the water use efficiency of crops by determining irrigation time and irrigation quota according to the critical period of crop water demand; thirdly, the crop planting structure should be adjusted according to the rainy season. Reasonable arrangement of crop distribution, such as crop water demand characteristics, can make full use of precipitation and alleviate the contradiction between irrigation and water use.

In the study, a comprehensive calculation method for the total water consumption of various crops was established, and the main crop such as wheat was selected for detailed analysis. The crop growth period was divided into smaller periods to improve the calculation accuracy. According to the export-oriented characteristics of agriculture in the Yellow River Basin, the calculation method of agricultural water footprint in the Yellow River Basin is put forward. Zhuo et al. (2016) studied the changes of water footprint and blue-green water of some crops in the Yellow River basin from 1961 to 2009. The spatial distribution of the results is relatively stable. The spatial distribution of agricultural water footprint and blue and green water in this study have the similar spatial correlation with the results of Zhuo et al.'s study.

The calculation of water consumption is mainly based on the empirical formula of reference crop ET and crop coefficient provided by FAO. The adaptability of this method to the study area needs further study. At present, there are many actual ET products available, such as (MODIS Global Evapotranspiration Project, MOD16), which can provide 8-day ET data. It is worth studying to compare the results based on the MOD16 or other ET products with the results of this study. At the same time, the spatial resolution of 5 arc-minutes is adopted, which may not be applicable to some smaller irrigation areas. Therefore, it is very important to study crop distribution on higher spatial resolution scale, which involves near-surface remote sensing, field mapping, high-resolution image data, and the collection of corresponding agricultural sector data. The above research will be launched in the near future to achieve in-depth study of regional agricultural water footprint and green water.

Acknowledgements. This work was partially supported by the MOE (Ministry of Education in China) Liberal arts and Social Sciences Foundation (Grant No. 19YJCZH228), and the Heilongjiang Natural Science Foundation Project (Grant No. E2018006), the National Natural Science Foundation of China (Grant No. 41401042), and 2018 Guizhou University of Finance and economics talent recruitment project (Grant No. 2018YJ27).

\section{REFERENCES}

[1] Allen, R. G., Pereira, L. S., Raes, D., Smith, M. (1998): Crop EvapotranspirationGuidelines for Computing Crop Water Requirements-FAO Irrigation and Drainage Paper No. 56. - FAO, Rome, Italy. 
[2] Bai, L., Cai, J., Liu, Y., Chen, H., Zhang, B., Huang, L. (2017): Responses of field evapotranspiration to the changes of cropping pattern and groundwater depth in large irrigation district of yellow river basin. - Agricultural Water Management 188: 1-11.

[3] Barbagallo, S., Consoli, S., D’Urso, G., Gaggia, R. G., Toscano, A. (2004): Remote sensing of crop water requirements in orange orchards using high-spatial-resolution sensors. - Proceedings of SPIE - The International Society for Optical Engineering 5232(3): 119-127.

[4] Calera, A., Campos, I., Osann, A., D’Urso, G., Menenti, M. (2017): Remote sensing for crop water management: from et modelling to services for the end users. - Sensors 17(5): 1104.

[5] Fader, M., Gerten, D., Thammer, M., Heinke, J., Lotzecampen, H., Lucht, W., Cramer, W. (2011): Internal and external green-blue agricultural water footprints of nations, and related water and land savings through trade. - Hydrology \& Earth System Sciences 15: 1641-1660.

[6] Feng, K., Siu, Y. L., Guan, D., Hubacek, K. (2012): Assessing regional virtual water flows and water footprints in the Yellow River Basin, China: a consumption based approach. - Applied Geography 32(2): 691-701.

[7] Gonçalves, J. M., Pereira, L. S., Fang, S. X., Dong, B. (2007): Modelling and multicriteria analysis of water saving scenarios for an irrigation district in the upper yellow river basin. - Agricultural Water Management 94(1-3): 93-108.

[8] González-Dugo, M. P., Escuin, S., Cano, F., Cifuentes, V., Padilla, F. L. M., Tirado, J. L., Oyonarte, N., Fernández, P., Mateosd, L. (2013): Monitoring evapotranspiration of irrigated crops using crop coefficients derived from time series of satellite images. ii. application on basin scale. - Agricultural Water Management 125: 92-104.

[9] Hoff, H., Falkenmark, M., Gerten, D., Gordon, L., Karlberg, L., Rockstrom, J. (2010): Greening the global water system. - Journal of Hydrology 384(3-4): 177-186.

[10] Li, J., Zhu, T., Mao, X., Adeloye, A. J. (2016): Modeling crop water consumption and water productivity in the middle reaches of Heihe River basin. - Computers and Electronics in Agriculture 123: 242-255.

[11] Mishra, S. K., Singh, V. P. (2007): Soil conservation service curve number (SCS-CN) methodology. - Water Science \& Technology Library 22(3): 355-362.

[12] Mo, X. G., Liu, S. X., Lin, Z. H., Guo, R. P. (2009): Regional crop yield, water consumption and water use efficiency and their responses to climate change in the north china plain. - Agriculture Ecosystems \& Environment 134(1): 67-78.

[13] Serrano-Coronel, G., Chipana-Rivera, R., Moreno-Pérez, M. F., Roldán-Cañas, J. (2018): Study of vertical water flows contribution to the crop water consumption in suka kollus, using a mixed drainage system. - Agricultural Water Management 206: 86-94.

[14] Sikorska, A. E., Viviroli, D., Seibert, J. (2018): Effective precipitation duration for runoff peaks based on catchment modelling. - Journal of Hydrology 556: 510-522.

[15] Veettil, A. V., Mishra, A. K. (2016): Water security assessment using blue and green water footprint concepts. - Journal of Hydrology 542: 589-602.

[16] Wang, X., Huo, Z., Guan, H., Guo, P., Qu, Z. (2018): Drip irrigation enhances shallow groundwater contribution to crop water consumption in an arid area. - Hydrological Processes 32(6): 747-758.

[17] Wei, Y., Tang, D., Ding, Y., Agoramoorthy, G. (2016): Incorporating water consumption into crop water footprint: a case study of China's south-north water diversion project. Science of the Total Environment 545-546: 601-608.

[18] Xiang, X., Svensson, J., Jia, S. (2017): Will the energy industry drain the water used for agricultural irrigation in the yellow river basin? - International Journal of Water Resources Development 33(1): 69-80.

[19] Yin, J., Wang, H., Cai, Y. (2016): Water footprint calculation on the basis of input-output analysis and a biproportional algorithm: a case study for the Yellow River Basin, China. Water 8(9): 363. 
[20] Yin, J., Fu, Q., Xing, Z., Lu, Y., Ou, Z. (2017): Agricultural water-saving potential for Guanzhong irrigation areas under different guaranteed rates of precipitation. - Applied Ecology and Environmental Research 15(4): 1255-1274.

[21] You, L., Wood, S., Wood-Sichra, U., Wu, W. Liu, Z., Li., Z., Zhou, Q., Tang, H. (2014): Generating global crop distribution maps: from census to grid. - Agricultural Systems 127: 53-60.

[22] Zhang, B. Z., Kang, S. Z., Zhang, L., Du, T. S., Li, S. E., Yang, X. Y. (2010): Estimation of seasonal crop water consumption in a vineyard using Bowen ratio-energy balance method. - Hydrological Processes 21(26): 3635-3641.

[23] Zhang, W., Zha, X., Li, J., Wei, L., Ma, Y., Fan, D., Li, S. (2014): Spatiotemporal change of blue water and green water resources in the headwater of Yellow River Basin, China.Water Resources Management 28(13): 4715-4732.

[24] Zhuo, L., Mekonnen, M. M., Hoekstra, A. Y. (2014): Sensitivity and uncertainty in crop water footprint accounting: a case study for the Yellow River basin. - Hydrology and Earth System Sciences 18(6): 2219-2234.

[25] Zhuo, L., Mekonnen, M. M., Hoekstra, A. Y., Wada, Y. (2016): Inter- and intra-annual variation of water footprint of crops and blue water scarcity in the yellow river basin (1961-2009). - Advances in Water Resources 87: 29-41.

[26] Zuo, D., Xu, Z., Peng, D., Song, J., Cheng, L., Wei, S., Abbaspour, K. C., Yang, H. (2015): Simulating spatiotemporal variability of blue and green water resources availability with uncertainty analysis. - Hydrological Processes 29(8): 1942-1955. 